\title{
Seasonal variation in the occurrence and abundance of mangrove macroalgae in a Malaysian estuary
}

\begin{abstract}
Mangrove macroalgae produce substantial proportion of biomass, which contributes to the coastal ecosystems. Relatively less is known for the seasonal variation in the occurrence and biomass of mangrove associated macroalgae. Consequently, mangrove macroalgae epiphytic on the pneumatophores of Avicennia marina (Forsk.) Vierh., were sampled from the Miri estuary of Sarawak during the four seasons of Malaysia namely southwest monsoon, northeast monsoon, and two inter-monsoons to elucidate seasonal variation in the occurrence and biomass production of macroalgae. Over the sample period, 11 species of mangrove macroalgae were identified from 6 genera. Six of these species such as Caloglossa leprieurii (Montagne) J.Agardh, C. adhaerens R.J.King \& Puttock, C. stipitata E.Post, C. ogasawaraensis Okamura, Bostrychia kelanensis Grunow and Dictyota sp. were found to be common in each sample time. Considering four seasonal samples, maximum frequency of occurrence was observed for C. ogasawaraensis $(66 \pm 10 \%)$ and maximum biomass was observed for B. kelanensis $\left(248 \pm 95 \mathrm{~g} \mathrm{~m}^{-2}\right)$. Marked seasonal variations were observed in the frequencies of occurrence and the biomass for the most of the dominant macroalgal species. To the best of our knowledge this is the first time to report the seasonal pattern data for occurrence and abundance of macroalgae from the mangrove systems of Malaysia.
\end{abstract}

Keyword: Mangrove macroalgae; Pneumatophores; Seasonal distribution; Sarawak; Malaysia 